\title{
Does Loneliness Have a Cost? A Population-Wide Study of the Association Between Loneliness and Healthcare Expenditure
}

\author{
Rachelle Meisters ${ }^{1 *}$, Daan Westra ${ }^{1}$, Polina Putrik ${ }^{1,2}$, Hans Bosma $^{3}$, Dirk Ruwaard ${ }^{1}$ and \\ Maria Jansen ${ }^{1,2}$
}

${ }^{1}$ Department of Health Services Research, Care and Public Health Research Institute (CAPHRI), Faculty of Health, Medicine and Life Sciences (FHML), Maastricht University, Maastricht, Netherlands, ${ }^{2}$ Academic Collaborative Centre for Public Health Limburg, South Limburg Medical Health Service (GGD South Limburg), Heerlen, Netherlands, ${ }^{3}$ Department of Social Medicine, Care and Public Health Research Institute (CAPHRI), Faculty of Health, Medicine and Life Sciences (FHML), Maastricht University, Maastricht, Netherlands

Objectives: Loneliness has been associated with unhealthy behavior, poorer health, and increased morbidity. However, the costs of loneliness are poorly understood.

Methods: Multiple sources were combined into a dataset containing a nationally representative sample $(n=341,376)$ of Dutch adults $(18+)$. The association between loneliness and total, general practitioner (GP), specialized, pharmaceutical, and mental healthcare expenditure was tested using Poisson and Zero-inflated negative binomial models, controlling for numerous potential confounders (i.e., demographic, socioeconomic, lifestyle-related factors, self-perceived health, and psychological distress), for four age groups.

Results: Controlling for demographic, socioeconomic, and lifestyle-related factors, loneliness was indirectly (via poorer health) associated with higher expenditure in all categories. In fully adjusted models, it showed a direct association with higher expenditure for GP and mental healthcare ( 0.5 and $11.1 \%$, respectively). The

\section{OPEN ACCESS}

*Correspondence:

Rachelle Meisters

r.meisters@maastrichtuniversity.nl

Received: 08 July 2020 Accepted: 07 September 2020

Published: 02 February 2021

Citation:

Meisters $R$, Westra $D$, Putrik $P$, Bosma H, Ruwaard $D$ and Jansen $M$ (2021) Does Loneliness Have a Cost?

A Population-Wide Study of the

Association Between Loneliness and Healthcare Expenditure. Int J Public Health 1:581286. doi: 10.3389/ijph.2021.581286 association with mental healthcare expenditure was stronger in younger than in older adults (for ages $19-40$, the contribution of loneliness represented $61.8 \%$ of the overall association).

Conclusion: Loneliness contributes to health expenditure both directly and indirectly, particularly in younger age groups. This implies a strong financial imperative to address this issue.

Keywords: social determinants of health, loneliness, healthcare expenditure, Netherlands, health inequalities

\section{INTRODUCTION}

In recent years, loneliness has become a growing public health issue. Approximately $10 \%$ of European citizens (18+) feel left out of society and the problem is greater for unemployed and low-income groups (1). While most modern Western societies perceive loneliness as a problem of old age (2), it is a growing problem in younger age groups $(2,3)$. Extensive research has related poor 
health to loneliness (4), and conversely, loneliness to unhealthy behaviors $(3,5)$, worse physical $(6-10)$ and mental health $(3,10)$, and increased morbidity and mortality (10). In addition to the social effects of loneliness, it can thus also have a considerable impact on the ever-increasing healthcare costs of most Western countries (11). While it is imperative for well-informed policy decisions, such economic consequences of loneliness remain poorly understood.

Despite the growing awareness of loneliness as a health issue (1) and the increasing pressure on healthcare resources, research on the healthcare costs that could be attributed to loneliness is scarce. A recent review by Mihalopoulos et al. (12) identified 12 relevant studies conducted in the last 10 years. Four of these studies were cost of illness studies, which assessed various combinations of inpatient, outpatient, medical, non-medical (residential care, social services, administrative costs), or indirect costs (informal care) associated with loneliness in older adults (13-16). While most of these found that loneliness was associated with excess healthcare costs, one reported that it is associated with lower inpatient healthcare expenditure, suggesting that loneliness might act as a barrier to accessing healthcare (16). Four economic evaluation studies reported that interventions addressing loneliness may provide good value for money (12). Another five return on investment studies of loneliness interventions studied various non-monetary values, making results difficult to compare and validate (12). While some evidence thus suggests that lonely older people do have higher health care costs, little is known about other population groups (12). Furthermore, most studies focused on a limited amount of expenditure categories (e.g., only inpatient hospital care), control for a limited amount of confounding variables, and utilize relatively small samples (12).

The present study addresses the question "what is the relation between loneliness and healthcare expenditure?" using a large, nationally representative, sample of the general adult (18+) population. We strive to understand the association with health expenditures in the context of a broad range of potential confounding variables that are known to have an association with healthcare expenditure. As the impact of loneliness might differ between age groups and expenditure categories, we investigate the association between loneliness and general practitioner (GP), pharmaceutical, mental healthcare, specialized, and total curative healthcare expenditure in four different age groups (i.e., 19-40, 41-64, 65-80, and 81 years and older). Given the relation between loneliness and worse physical (6-10) and mental health (3, 10 ), we expect that loneliness is indirectly (i.e., through poorer health) associated with higher expenditure in all expenditure categories (hypothesis 1). Furthermore, we expect loneliness to be directly associated with higher a) mental healthcare and b) pharmaceutical expenditure (hypothesis 2a-b) because individuals could perceive loneliness as a mental health condition in itself, which can be treated by a mental healthcare provider or using pharmaceuticals. Additionally, lonely individuals may visit easily accessible and free-of-charge GP's more often in search of social interactions (17). Therefore, we expect loneliness to be directly associated with higher GP expenditure (hypothesis 3). Lonely individuals of older age may lack support networks and thus seek relief for their loneliness through increased contacts with their GP's, as opposed to their younger counterparts. Therefore, we expect differences in the associations between loneliness and GP expenditures between age groups (hypothesis 3a). For other costs categories, no a priori hypothesis was made for directions of differences by age as prior research is scarce. Explorative analyses will be undertaken. Lastly, we expect that the net effect of the previous hypotheses will result in a direct and an indirect increase of total healthcare expenditure (hypothesis 4). The hypothesized relationships in this study are visualized in Figure 1. The results of our work should provide insight to public health policy-makers who seek to understand the impact of loneliness on healthcare expenditure and economic aspects of programs targeting at alleviating loneliness.

\section{METHODS}

\section{Setting}

We use a time-lagged design to study associations between loneliness and healthcare expenditure in the Netherlands in 2016 and 2017. Roughly, 31 billion euros were spent on curative care through compulsory health insurance schemes in the country in 2016 (18). This amounts to approximately $€ 1800$ per capita, or $4.3 \%$ of the Dutch GDP, ranking the Netherlands 13th of the 32 OECD countries on curative health expenditure (18). Dutch citizens are insured for GP services, specialized care, pharmaceuticals, and mental healthcare amongst others through compulsory basic health insurance (19).

\section{Data Sources and Linkage}

Our dataset combines individual-level data from two sources covering the year 2016 and one source covering 2017. Firstly, we used the Health Survey of the Public Health Service 2016. It is a nationwide survey completed every 4 years by adults aged 19 years and older $(n=457,150)$. It covers various subjects including socioeconomic status (SES), social contacts, lifestyle, and general (physical and mental) health (20). It is completed by either paper and pencil, internet, telephone or face-to-face interviews. Secondly, we used data provided by Statistics Netherlands for 2016. These data included two administrative databases: the Personal Records database (PRB) and the Dutch Tax and Customs Administration data. The PRB is managed by municipalities and provided information about citizen's age, gender, and migration background. The Dutch Tax and Customs Administration data provided income records for each citizen, for both the personal and household level. Thirdly, we used the 2017 Dutch healthcare claims dataset provided by Vektis, the healthcare information center. It is a national dataset of reimbursed individuals' claims covered by the basic insurance package in a given year. These data have previously been used to explore associations of neighborhood disadvantage with healthcare expenditure (21). All datasets were linked via pseudonymized personal social security codes in the secured environment of Statistics Netherlands. After data linkage, our sample included 341,376 respondents. 


\section{Hypothesized relationships between loneliness and health expenditures.}

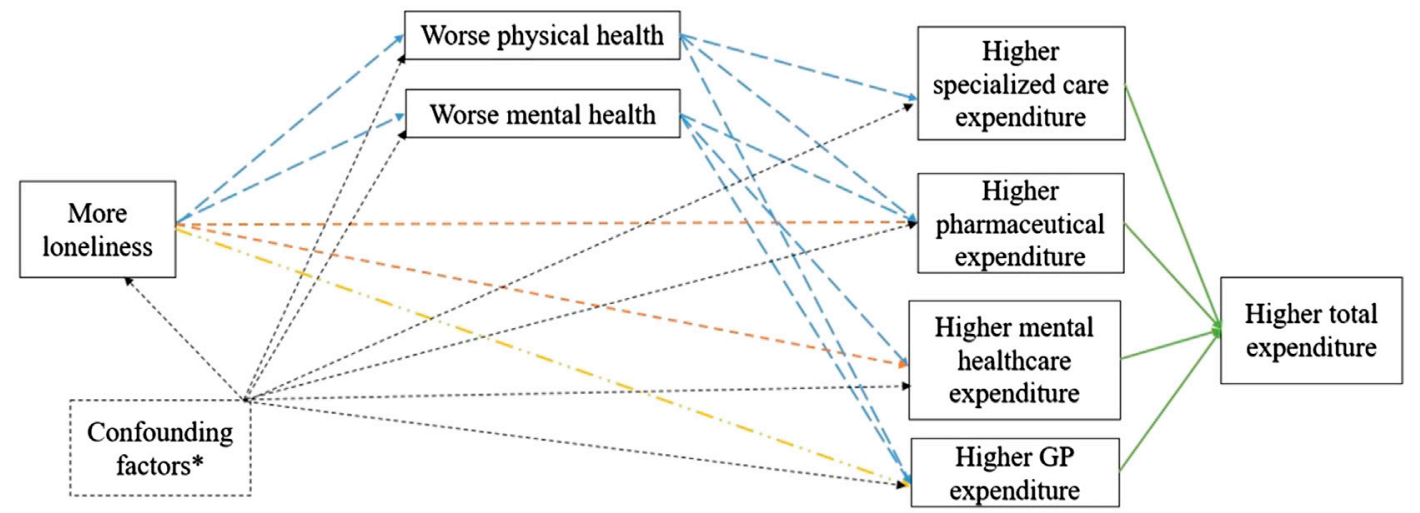

Hypothesis 1: loneliness is indirectly related to higher expenditure through poorer physical and mental health (blue arrows)

Hypothesis $2 \mathrm{a}$ and $\mathrm{b}$ : loneliness is directly related to higher pharmaceutical and mental healthcare expenditure (orange arrows)

Hypothesis 3: loneliness is directly related to higher GP expenditure (yellow arrow)

Hypothesis 4: net effect of the previous hypotheses will result in a direct and an indirect increase of total healthcare expenditure (green arrows)

* Confounding factors considered in this study are age, gender, migration background, marital status, education, income level, and income inadequacy.

FIGURE 1 | Hypothesized relationships between loneliness and health expenditures. Hypothesis 1: loneliness is indirectly related to higher expenditure through poorer physical and mental health (blue arrows). Hypothesis $2 \mathrm{a}$ and b: loneliness is directly related to higher pharmaceutical and mental healthcare expenditure (orange arrows). Hypothesis 3: loneliness is directly related to higher GP expenditure (yellow arrow). Hypothesis 4: net effect of the previous hypothesis will result in a direct and an indirect increase of total healthcare expenditure (green arrows). ${ }^{*}$ Confounding factors considered in this study are age, gender, migration background, marital status, education, income level, and income inadequacy (The Netherlands, 2020).

\section{Measures \\ Dependent Variables}

We used five dependent variables. These are 1) GP, 2) mental healthcare, 3) pharmaceutical, 4) specialized healthcare, and 5) total healthcare expenditure for the year 2017. Total healthcare expenditure is the sum of all expenditure individuals incurred under the basic health insurance plan. This includes expenditure for primary care, mental health care, pharmaceutical care, and hospital care (these four accounted for $88 \%$ of total expenditure in 2017), as well as several smaller expenditure categories such as dental-, paramedic-, obstetric-, geriatric-, cross-border care, and ambulance costs (19). In the Netherlands, GP expenditure consists of an annual enrollment fee per individual and a feefor-service component. We use the fee-for-service component as our GP expenditure variable (i.e., expenditure associated with GP consultations). Specialized care expenditure include expenditure for specialized in-patient and outpatient clinics including inhospital medication and excluding mental health hospitals. Pharmaceutical expenditure includes all prescription pharmaceuticals provided outside the hospital. Mental healthcare expenditure includes expenditure for basic and specialized (long and short-term) mental health services care in ambulatory or hospital settings.

\section{Independent Variable}

The main factor of interest in this study is loneliness, a selfreported measure based on the 11-item de Jong Gierveld scale (22), taken from the Health Survey. Work by Van Tilburg and De Jong Gierveld (23) based cutoff scores on individual's self- assessed level on loneliness in order to keep cutoff scores more in line with individuals own perception rather than arbitrary cutoff scores. Loneliness is subsequently categorized as follows: "not lonely" (scores between 0 and 2, reference group), "somewhat lonely" (scores between three and 8), "severe loneliness" (scores of nine or 10), and "very severe loneliness" (score of 11).

\section{Potential Confounders}

Potential confounders included demographic, SES, lifestylerelated factors and general health measures. The demographic factors were age (19-40 as the reference group, 41-64, 65-80, and 81 years and older), gender (binary variable with male as the reference group), migration background (Dutch-born as the reference group, western migration background, and nonwestern migration background), and marital status (selfreported as "living together or married" as the reference group, "single," "widowed," or "divorced"). The three former variables were taken from the BRP, while the latter was taken from the Health Survey. The SES-variables were individuals' highest level of completed education (higher vocational education or university degree as the reference group, secondary or middle vocational education, lower vocational education, and primary education), self-reported income adequacy ("adequate, no concerns" as the reference group, "adequate, minor concerns," "inadequate, some concerns," and "inadequate, major concerns"), and standardized household income based on the number of members in the household (divided it into quartiles based on the entire Dutch 
population, with highest quartile as reference group). The two former measures were taken from the Health Survey and the latter from the Dutch Tax Authority.

The lifestyle-related factors include body mass index (BMI), alcohol consumption, smoking behavior, and physical activity level. These were all taken from the Health Survey and are selfreported measures. BMI was categorized in "normal" (between 18.5 and 25, reference group), "underweight" (less than 18.5), "overweight" (between 25 and 30), and "obese" (over 30) (24). Alcohol consumption consists of three mutually exclusive categories; "never consuming alcohol" (reference group), "regular alcohol consumption," or "excessive alcohol consumption" (more than 21 alcoholic beverages a week for men and more than 14 for women). The norms for alcohol consumption are based on the guidelines by the Dutch Health Council. Smoking habits were categorized as "never smoked before" (reference group), "former smoker," and "current smoker." Physical activity was dichotomized as being sufficient [at least $30 \mathrm{~min}$ of reasonably intensive activity (like walking) per day for at least 5 days a week, or a minimum of 20 min intense activity (like running) per day for at least 3 days a week, reference group] or insufficient based on the Dutch Health Council's guidelines for sufficient physical activity (25).

General health indicators were also self-reported measures from the Health Survey: self-reported health, chronic disease, and psychological distress. Self-rated health was based on the following question; "In general, would you say your health is ...." Answer categories include "excellent," "very good," "good," "fair," and "poor." The measure was dichotomized as either "excellent [very] good" health (reference group) or "fair or poor" health (26). Having at least one chronic disease was based on the question "Do you have one or more long-term diseases (expected duration 6 months or longer)." Answers were either no (i.e., no chronic disease) (reference group) or yes (i.e., at least one chronic disease). Psychological distress was measured with the Kessler psychological distress scale (K10) (27). The scores for these 10 questions were categorized as "none or low" (scores between 10 and 15, reference group), "moderate" (scores between 16 and 29), or "high" (scores between 30 and 50) psychological distress.

Lastly, as mode of completing the survey (internet, paper and pencil, telephone or face-to-face interviews) can impact the answers (28), it was adjusted for in each model.

\section{Statistical Analyses}

The survey sample was weighted to represent the overall Dutch population, based on age, gender, ethnicity and urbanization levels. The regression analyses accounted for survey design.

Healthcare expenditure data are often skewed and/or contain excessive zeros, requiring specific analytical approaches (29). Vuong and Zero-Inflated Poisson likelihood-ratio tests guided the choice of final model (30). We consequently performed our analyses using Poisson (for total expenditure) and zero-inflated negative binomial (ZINB) regressions (for GP, specialized, pharmaceutical, and mental healthcare expenditure). In ZINB regressions, the output is twofold. The first part provides the Incidence Rate Ratio (IRR) for non-zero expenditure, assuming a
Poisson distribution. Second, the inflated part of the output represents the odds of incurring zero expenditure (vs. any expenditure). For this study, the IRR represents the expected expenditure incurred for a lonely person (somewhat, severe or very severely lonely), divided by the expected expenditure incurred for a non-lonely person, accounting for covariates.

For each expenditure category, 6 models were computed by adding new covariates at each step. That is, expenditure were first modeled with loneliness as the only predictor in model 1 . Next, demographic variables were added in model 2 , SES variables were added in model 3, lifestyle variables were added in model 4, selfperceived health variables (self-rated health and chronic disease) were added in model 5, and the psychological distress variable was added in model 6 , which represents the fully adjusted model. The mode of completing the survey was included in all models 1-6. To determine the need for subgroup analyses, we tested for interaction effects between loneliness and age in the different expenditure categories. Lastly, to estimate expenditure of loneliness, marginal expenditure estimates were obtained from the models with all covariates held constant at their average value. These were than extrapolated to the entire Dutch population for the year 2017. The significance level was set at alpha $=5 \%$. All analyses were performed in Stata 15 (31).

\section{RESULTS}

\section{Descriptive Statistics}

Table 1 reports the descriptive statistics. The mean (SD) age was 59.3 (16.9) years and $52.7 \%$ of the sample was female. The prevalence of loneliness was $41.8 \%$, with $33.5 \%$ of the respondents experiencing some loneliness, 5.4\% severe, and $2.9 \%$ very severe loneliness. Chronic diseases were reported at least once for $39.3 \%$ of the sample, and $26.1 \%$ reported their health as (very) bad or fair. Over half of the population reported none or low psychological distress $(60.7 \%), 34.8 \%$ reported moderate, and $4.5 \%$ high psychological distress. Loneliness was prevalent in all age groups, however more common in older age groups. The prevalence of loneliness was $34.8 \%$ in $19-40$ yearolds, $39.7 \%$ in $41-64$ year-olds, $43.7 \%$ in $65-80$ year-olds and $57.4 \%$ for respondents of 81 years and older, see Table 2.

\section{Assoiations between loneliness and expenditure categories}

Table 3 reports the associations of loneliness with different categories of healthcare expenditure. In models 1 to 4 , loneliness is associated with higher expenditures, albeit with smaller (and in specialized care some non-significant) IRRs in models 4 , partially confirming hypothesis 4 . After controlling for all potential confounders (model 6, Table 3), loneliness was still directly associated with increased mental healthcare expenditure, confirming hypothesis $2 \mathrm{a}$. That is, the IRR for loneliness categories ranged between $1.17(1.04-1.33)$ and 1.31 (1.08; 1.58), indicating higher expenditure in mental healthcare for lonely people compared to non-lonely people. Model 6 also indicates a small direct increase of GP expenditure for 
TABLE 1 | Sample characteristics $(n=341,376)$ (The Netherlands, 2020).

\begin{tabular}{|c|c|c|c|c|c|}
\hline \multicolumn{2}{|l|}{ Sample characteristics } & \multirow{2}{*}{$\begin{array}{c}\boldsymbol{n}(\%) \\
55,817(16.4 \%)\end{array}$} & \multicolumn{2}{|c|}{ Sample characteristics } & \multirow{2}{*}{$\begin{array}{c}\boldsymbol{n} \text { (\%) } \\
96,417(28.2 \%)\end{array}$} \\
\hline $\operatorname{Age}^{a}$ & $19-40$ & & Physical activity ${ }^{\mathrm{b}}$ & Insufficient & \\
\hline & $41-64$ & $118,814(34.8 \%)$ & & Sufficient & 244,959 (71.8\%) \\
\hline & $65-80$ & $143,231(42.0 \%)$ & $\mathrm{BMI}^{\mathrm{b}}$ & Underweight $(<18,5)$ & $4,260(1.2 \%)$ \\
\hline & $81+$ & 23,514 (6.9\%) & & Normal $(18,5-25)$ & 155,082 (45.4\%) \\
\hline \multirow[t]{2}{*}{ Gender $^{\mathrm{a}}$} & Male & $161,576(47.3 \%)$ & & Overweight (25-30) & $131,625(38.6 \%)$ \\
\hline & Female & $179,800(52.7 \%)$ & & Obese $(30>)$ & $50,409(14.8 \%)$ \\
\hline \multirow[t]{3}{*}{ Migration background ${ }^{a}$} & Dutch-born & $300,426(88.0 \%)$ & Alcohol consumption ${ }^{\mathrm{b}}$ & Never & 33,799 (9.9\%) \\
\hline & Western migration background & 28,697 (8.4\%) & & Regular consumption & $280,475(82.2 \%)$ \\
\hline & Non-western migration background & 12,253 (3.6\%) & & Excessive & 27,102 (7.9\%) \\
\hline \multirow[t]{4}{*}{ Marital status $^{a}$} & Married/co-habitant & $248,688(72.8 \%)$ & Smoking ${ }^{b}$ & Never smoked & $138,456(40.6 \%)$ \\
\hline & Single & 36,338 (10.6\%) & & Former smoker & $147,920(43.3 \%)$ \\
\hline & Widowed & 23,533 (6.9\%) & & Current smoker & $55,000(16.1 \%)$ \\
\hline & Divorced & 32,817 (9.6\%) & Chronic disease ${ }^{\mathrm{b}}$ & None & $207,262(60.7 \%)$ \\
\hline \multirow[t]{4}{*}{ Education $^{\mathrm{b}}$} & Primary school & $19,897(5.8 \%)$ & & At least one & $134,114(39.3 \%)$ \\
\hline & Lower vocational & $106,023(31.1 \%)$ & Self-rated health ${ }^{b}$ & Excellent, (very) good & $252,118(73.8 \%)$ \\
\hline & Middle vocational/secondary & 107,937 (31.6\%) & & Fair, poor & $89,258(26.2 \%)$ \\
\hline & Higher vocational/university & 107,519 (31.5\%) & Psychological distress ${ }^{b}$ & None or low & 207,079 (60.6\%) \\
\hline \multirow[t]{4}{*}{ Household income quartile ${ }^{a}$} & $0-25 \%$ & $43,471(12.7 \%)$ & & Moderate & $1198,853(34.8 \%)$ \\
\hline & $26-50 \%$ & $86,582(25.4 \%)$ & & High & $15,444(4.6 \%)$ \\
\hline & $51-75 \%$ & $99,759(29.2 \%)$ & Loneliness $^{b}$ & Not lonely & $198,705(58.2 \%)$ \\
\hline & $76-100 \%$ & $111,564(32.7 \%)$ & & Somewhat lonely & 114,428 (33.5\%) \\
\hline \multirow[t]{6}{*}{ Self-reported income adequacy ${ }^{b}$} & Inadequate, major concerns & $9,690(2.8 \%)$ & & Severely lonely & 18,393 (5.4\%) \\
\hline & Inadequate, some concerns & $34,973(10.2 \%)$ & & Very severely lonely & $9,850(2.9 \%)$ \\
\hline & Adequate, minor concerns & $117,764(34.5 \%)$ & Completing & Paper and pencil & $149,630(43.8 \%)$ \\
\hline & Adequate, no concerns & 178,949 (52.4\%) & Survey & Internet & 191,249 (56.0\%) \\
\hline & & & & Face-to-face & $337(0.1 \%)$ \\
\hline & & & & Telephone & $160(0.05 \%)$ \\
\hline
\end{tabular}

BMI, body mass index; GP, general practitioner.

${ }^{a}$ Registry data variables.

${ }^{b}$ Self-reported variables extracted from Health Survey.

TABLE 2 | Prevalence loneliness across age groups N (\%) (The Netherlands, 2020).

\begin{tabular}{|c|c|c|c|c|}
\hline & $19-40$ & $41-64$ & $65-80$ & $81+$ \\
\hline Not lonely & $36,383(65.2 \%)$ & 71,665 (60.3\%) & 80,639 (56.3\%) & $10,018(42.6 \%)$ \\
\hline Somewhat lonely & $15,123(27.1 \%)$ & 36,985 (31.1\%) & $51,611(36.0 \%)$ & 10,709 (45.5\%) \\
\hline Severely lonely & 2,870 (5.1\%) & 6,365 (5.4\%) & 7,228 (5.0\%) & 1,930 (8.2\%) \\
\hline Very severely lonely & $1,441(2.6 \%)$ & 3,799 (3.2\%) & $3,753(2.6 \%)$ & 857 (3.6\%) \\
\hline
\end{tabular}

individuals reporting higher levels of loneliness [1.08 $(1.04-1.13)]$, in line with hypothesis 3. However, the association of very severe loneliness with pharmaceutical expenditure was no longer statistically significant $[1.00$ $(0.85-1.18)]$ in model 6 , rejecting hypothesis $2 \mathrm{~b}$. The association between very severe loneliness and specialized care expenditure was negative in model 6 [i.e., IRR of 0.88 $(0.80-0.97)]$.

\section{Marginal Expenditure of Loneliness}

Table 4 reports the point estimate of marginal spending of loneliness (in million $€$ ) for the different healthcare categories in 2016, with the corresponding 95\% confidence interval, and the percentage of overall annual spending in each category. In the fully adjusted model (model 6), loneliness was associated with higher expenditure for mental and GP care (confirming hypothesis $2 \mathrm{a}$ and 3 ) but not for other expenditure categories.
For GP expenditure, loneliness was associated with 5.8 million euros (4.5-7.1), or $0.8 \%$ of the total annual GP spending (Table 4). For mental healthcare, loneliness was associated with 340.2 million euros (314.7-365.8), or $10.3 \%$ of the annual mental healthcare spending. For total healthcare and specialized care expenditure, loneliness was associated with $1.0 \%$ [435.4 million euros $(-494.8$ to -376.1$)$ ], and $2.0 \%$ [449.8 million (-474.3 to -425.2$)$ ] fewer spending, rejecting hypothesis 4 .

\section{Subgroup Analyses}

The interaction effects between age and loneliness were significant for total, pharmaceutical and mental healthcare, indicating a different association between loneliness and expenditure across age groups for these categories. Figure 2 (Supplementary Appendix) visualizes the spending patterns incurred per expenditure category for non-lonely, somewhat lonely, severely lonely, and very severely lonely individuals in 
TABLE 3 | Associations of loneliness with total healthcare, GP, specialized, pharmaceutical, and mental healthcare expenditure (The Netherlands, 2020).

\begin{tabular}{|c|c|c|c|c|c|c|c|}
\hline & & 1. Loneliness & $\begin{array}{l}\text { 2. Demographic } \\
\text { and loneliness }\end{array}$ & $\begin{array}{l}\text { 3. Demographic, } \\
\text { SES, and } \\
\text { loneliness }\end{array}$ & $\begin{array}{l}\text { 4. demographic, } \\
\text { SES, lifestyle, } \\
\text { and loneliness }\end{array}$ & $\begin{array}{l}\text { 5. Demographic, } \\
\text { SES, lifestyle, } \\
\text { self-perceived } \\
\text { health, } \\
\text { and loneliness }\end{array}$ & $\begin{array}{c}\text { 6. Total: } \\
\text { demographic, SES, } \\
\text { lifestyle, self- } \\
\text { perceived } \\
\text { health, psychological } \\
\text { distress, and } \\
\text { loneliness } \\
\end{array}$ \\
\hline & & $\begin{array}{l}\text { IRR 95\% } \\
\text { (CI) }\end{array}$ & $\begin{array}{l}\text { IRR 95\% } \\
\quad \text { (CI) }\end{array}$ & $\begin{array}{l}\text { IRR 95\% } \\
\quad \text { (CI) }\end{array}$ & $\begin{array}{l}\text { IRR 95\% } \\
\quad \text { (CI) }\end{array}$ & $\begin{array}{l}\text { IRR 95\% } \\
\quad \text { (CI) }\end{array}$ & $\begin{array}{l}\text { IRR 95\% } \\
\quad \text { (CI) }\end{array}$ \\
\hline Total & Not lonely & Ref & Ref & Ref & Ref & Ref & Ref \\
\hline \multirow[t]{3}{*}{ expenditure } & Somewhat lonely & 1.38 (1.33-1.42) & $1.24(1.20-1.28)$ & $1.17(1.13-1.20)$ & $1.14(1.10-1.18)$ & $1.00(0.97-1.03)$ & $0.96(0.93-0.99)$ \\
\hline & Severely lonely & $1.81(1.72-1.92)$ & $1.66(1.57-1.76)$ & 1.45 (1.37-1.53) & $1.38(1.31-1.46)$ & $1.04(0.99-1.10)$ & $0.96(0.91-1.02)$ \\
\hline & $\begin{array}{l}\text { Very severely } \\
\text { lonely }\end{array}$ & 2.10 (1.95-2.25) & $1.93(1.80-2.08)$ & 1.58 (1.47-1.70) & $1.50(1.39-1.61)$ & 1.05 (0.99-1.12) & $0.94(0.87-1.01)$ \\
\hline \multirow[t]{4}{*}{ GP Expenditure } & Not lonely & Ref & Ref & Ref & Ref & Ref & Ref \\
\hline & Somewhat lonely & 1.24 (1.22-1.25) & 1.18 (1.16-1.19) & $1.12(1.11-1.14)$ & $1.12(1.10-1.13)$ & $1.06(1.05-1.08)$ & $1.02(1.01-1.04)$ \\
\hline & Severely lonely & $1.53(1.49-1.57)$ & $1.45(1.41-1.49)$ & $1.32(1.28-1.36)$ & $1.30(1.26-1.33)$ & $1.16(1.13-1.20)$ & 1.07 (1.04-1.10) \\
\hline & $\begin{array}{l}\text { Very severely } \\
\text { lonely }\end{array}$ & $1.72(1.66-1.79)$ & $1.65(1.58-1.72)$ & $1.43(1.38-1.50)$ & $1.41(1.35-1.47)$ & $1.22(1.17-1.27)$ & $1.08(1.04-1.13)$ \\
\hline Specialized care & Not lonely & Ref & Ref & Ref & Ref & Ref & Ref \\
\hline \multirow[t]{3}{*}{ Expenditure } & Somewhat lonely & $1.11(1.06-1.16)$ & $1.05(1.00-1.11)$ & $1.01(0.96-1.07)$ & $1.01(0.96-1.06)$ & $0.93(0.88-0.98)$ & $0.94(0.90-0.98)$ \\
\hline & Severely lonely & $1.24(1.15-1.34)$ & 1.25 (1.14-1.37) & $1.15(1.05-1.26)$ & 1.12 (1.03-1.22) & $0.93(0.85-1.00)$ & $0.94(0.87-1.02)$ \\
\hline & $\begin{array}{l}\text { Very severely } \\
\text { lonely }\end{array}$ & $1.26(1.14-1.38)$ & $1.26(1.13-1.39)$ & 1.12 (1.01-1.24) & 1.09 (0.98-1.20) & $0.87(0.79-0.95)$ & $0.88(0.80-0.97)$ \\
\hline Pharmaceutical & Not lonely & Ref & Ref & Ref & Ref & Ref & Ref \\
\hline \multirow[t]{3}{*}{ Expenditure } & Somewhat lonely & $1.39(1.30-1.48)$ & $1.30(1.21-1.40)$ & $1.21(1.12-1.30)$ & $1.18(1.10-1.27)$ & $1.02(0.97-1.07)$ & $1.02(0.96-1.07)$ \\
\hline & Severely lonely & $1.76(1.58-1.99)$ & $1.76(1.52-2.04)$ & $1.52(1.31-1.76)$ & $1.47(1.26-1.71)$ & $1.05(0.94-1.18)$ & $1.04(0.94-1.16)$ \\
\hline & $\begin{array}{l}\text { Very severely } \\
\text { lonely }\end{array}$ & $1.90(1.71-2.12)$ & 1.77 (1.58-1.99) & $1.43(1.28-1.60)$ & $1.38(1.23-1.55)$ & $1.01(0.87-1.18)$ & $1.00(0.85-1.18)$ \\
\hline Mental & Not lonely & Ref & Ref & Ref & Ref & Ref & Ref \\
\hline healthcare & Somewhat lonely & $1.40(1.23-1.60)$ & 1.35 (1.19-1.53) & 1.29 (1.14-1.47) & $1.26(1.12-1.43)$ & $1.21(1.08-1.37)$ & $1.17(1.04-1.33)$ \\
\hline \multirow[t]{2}{*}{ Expenditure } & Severely lonely & $1.50(1.26-1.79)$ & $1.47(1.25-1.73)$ & $1.36(1.17-1.57)$ & $1.29(1.12-1.48)$ & $1.20(1.04-1.37)$ & 1.09 (0.95-1.26) \\
\hline & $\begin{array}{l}\text { Very severely } \\
\text { lonely }\end{array}$ & 1.85 (1.49-2.29) & $1.82(1.44-2.31)$ & 1.59 (1.34-1.97) & $1.62(1.33-1.97)$ & 1.47 (1.22-1.78) & $1.31(1.08-1.58)$ \\
\hline
\end{tabular}

Coefficients with $\mathrm{p}<0.05$ are in bold. GP, General practitioner; IRR, Incidence rate ratio; Cl, confidence interval; SES, Socioeconomic status. Results from Poisson and Zero-inflated negative binomial regressions ( $n=342,095)$. Inflated part reported in Supplementary Appendix A4.

the entire sample as well as in each age group (i.e., 19-40, 41-64, 65-80, and 81+). The corresponding IRR's and CI's of loneliness are reported in the Supplementary Appendix Table A1. Figure 2 and Supplementary Appendix Table A1 show that in the fully adjusted model (model 6) expenditure for adults over 40 (total and pharmaceutical) tend to be lower with increasing loneliness. Furthermore, age and loneliness do not have a significant interaction effect for GP expenditure, rejecting hypothesis 3a. Conversely, for the youngest age group (19-40), total expenditure is higher for severely lonely respondents compared to those who do not report loneliness. For mental healthcare, expenditure were even higher with very severe loneliness (IRR of 1.83 [1.34; 2.50]). In percentages, $6.3 \%$ of mental healthcare expenditure can be attributed to loneliness for age group $19-40,3.1 \%$ in 41-64 year-olds, $0.7 \%$ in 65-80 year-olds, and $0.1 \%$ fewer healthcare spending in $81+$ year-olds, in fully adjusted models. This represents $61.8,30.0,6.9$, and $1.3 \%$ of the overall contribution of loneliness and increased mental healthcare expenditure, per age group, respectively.

\section{DISCUSSION}

This study assessed the impact of loneliness on different types of healthcare expenditure, controlling for a range of individual demographic factors, socio-economic, lifestyle, and health indicators. The study is based on a linked, large dataset resulting in a nationally representative sample of the Dutch adult population $(n=341,376)$. Firstly, our results reveal that loneliness is associated with higher indirect spending in all expenditure categories (i.e., models 1-4), in line with hypothesis 1 . However, as the model was further adjusted for self-perceived health and psychological distress, the positive association between loneliness and expenditure reversed. The pattern of higher spending for lonely individuals namely only holds for mental healthcare and GP expenditure, confirming hypothesis $2 \mathrm{a}$ and 3 . Contrarily, the association is non-significant for pharmaceutical and total expenditure (hypotheses $2 \mathrm{~b}$ and 4 ) and is even reversed (i.e., lonely individuals incur fewer expenditure) for specialized healthcare expenditure. 
TABLE 4 | Marginal effects of loneliness for healthcare expenditure, extrapolated to entire Dutch 18+ population (The Netherlands, 2020).

\begin{tabular}{|c|c|c|c|c|c|}
\hline \multicolumn{6}{|c|}{ Million $€[95 \% \mathrm{Cl}]$ (\% category spending 2017$)$} \\
\hline & Total expenditure & GP expenditure & Specialized care expenditure & $\begin{array}{l}\text { Pharmaceutical } \\
\text { expenditure }\end{array}$ & $\begin{array}{c}\text { Mental healthcare } \\
\text { expenditure }\end{array}$ \\
\hline \multicolumn{6}{|c|}{ A. model 6: fully adjusted model } \\
\hline Somewhat lonely & $-315.1[-299.0$ to -331.2$](-0.7)$ & $3.3[3.0-3.5](0.5)$ & $-314.4[-289.0$ to -339.9$](-1.4)$ & $13.7[-4.4$ to 31.8$](0.3)$ & 243.4 [235.9-250.9] (7.4) \\
\hline Severely lonely & $-63.0[-100.4$ to -25.6$](-0.1)$ & $1.7[1.2-2.3](0.2)$ & $-69.2[-97.2$ to -41.3$](-0.3)$ & $6.0[-7.7$ to 19.8$](0.0)$ & $55.2[48.5-62.0](1.7)$ \\
\hline Very severely lonely & $-57.3[-95.3$ to -19.3$](-0.1)$ & $0.9[0.3-1.4](0.1)$ & $-66.2[-88.2$ to -44.2$](-0.3)$ & $-1.2[-14.3$ to 11.9$](0.1)$ & $41.6[30.3-52.8](1.3)$ \\
\hline Total & $-435.4[-494.7$ to -376.1$](-1.0)$ & $5.8[4.5-7.1](0.8)$ & $-449.9 .[-474.3$ to -425.4$](-2.0)$ & $18.5[-26.4$ to 63.4$](0.4)$ & $340.2[314.7-365.8](10.3)$ \\
\hline \multicolumn{6}{|c|}{$\begin{array}{l}\text { B. model 3: basic model + } \\
\text { SES }\end{array}$} \\
\hline Somewhat lonely & $1,273.2[1,248.1-1,298.5](3.0)$ & $17.8[19.2-20.3](2.8)$ & $200.2[194.0-206.4](0.9)$ & 201.9 [175.1-228.8] (4.3) & $497.1[455.9-538.3](15.1)$ \\
\hline Severely lonely & $647.6[578.0-717.3](1.5)$ & $9.7[8.9-10.4](1.4)$ & 190.8 [141.1-240.2] (0.8) & $95.6[66.4-124.7](2.1)$ & 212.7 [183.4-242.1] (6.5) \\
\hline Very severely lonely & $484.5[416.0-553.0](1.1)$ & $7.3[6.6-8.1](1.0)$ & $112.1[74.6-149.7](0.5)$ & $49.8[38.8-60.9](1.1)$ & 179.4 [143.0-215.8] (5.4) \\
\hline Total & $2,405.4[2,242.0-2,568.8](5.6)$ & $36.7[34.7-38.7](5.2)$ & $503.1[422.0-584.1](2.2)$ & $347.4[280.3-414.4](7.5)$ & 889.3 [782.3-996.2] (27.0) \\
\hline \multicolumn{6}{|l|}{ C. model 2: basic model } \\
\hline Somewhat lonely & $1,797.0[1,758.6-1,835.3](4.2)$ & 27.6 [26.9-28.3] (3.9) & $450.9[452.7-450.1](2.0)$ & $289.0[255.3-322.7](6.2)$ & 569.1 [521.1-617.2] (17.3) \\
\hline Severely lonely & $921.7[837.5-1,005.8](2.2)$ & $13.3[12.5-14.2](1.9)$ & $305.7[247.6-364.0](1.4)$ & $138.2[103.5-172.9](3.0)$ & $274.0[231.2-316.8](8.3)$ \\
\hline Very severely lonely & 744.0 [657.8-830.2] (1.7) & $10.8[9.8-11.8](1.5)$ & 208.8 [164.0-253.8] (0.9) & 85.5 [70.2-101.0] (1.8) & 253.9 [191.8-316.2] (7.7) \\
\hline Total & $3,462[3,253.8-3,671.4](8.1)$ & $51.8[49.3-54.3](7.3)$ & 965.4 [864.3-1,068.0] (4.3) & 512.7 [429.0-596.6] (11.0) & 1,097.0 [943.9-1,250.1] (33.3 \\
\hline
\end{tabular}

GP, general practitioner; Cl, confidence interval; SES, socioeconomic status. A. model 6 is the most extensive model, which includes loneliness, demographic, SES, lifestyle, self-perceived health and psychological distress. B. model 3 includes loneliness, demographic, and SES factors. C. model 2 is the basic model, which includes loneliness and demographic factors. Results from Poisson and Zero-inflated negative binomial regressions ( $\mathrm{n}=342,095)$.

The reduction (and in some cases reversing) of the association between loneliness and expenditure across the models suggests that the relationship between loneliness and expenditure might be mediated by self-perceived health and psychological distress. While this finding is in line with an extensive body of research that relates loneliness to worse physical (6-10) and mental health $(3,10)$, it complicates determining the total amount of (healthcare related) expenditure associated with loneliness, and hence rejecting or confirming hypothesis 4. As our results indicate, loneliness may be associated with an indirect increase of 3.5 billion euros $(8.1 \%)$ of total healthcare expenditure in the simplest estimation, or a direct decrease of 435.4 million euros $(1.0 \%)$ of total healthcare expenditure in the fully adjusted model. Lower expenditure associated with more loneliness are particularly apparent in specialized care. This could be explained by avoidance of care by lonely people compared to non-lonely people (16). Since specialized care represents a large part of total healthcare expenditure, the net results of all hypotheses result in lower total healthcare expenditure (hypothesis 4 ).

Further research, preferably with longitudinal designs, is required to clarify the underlying causal or complex mechanisms of loneliness and increased or decreased expenditure in all categories as well as between potential confounders. Longitudinal study designs could provide insight into effects of chronic loneliness over time on health care consumption. Furthermore, longitudinal designs could unravel underlying reverse causal mechanisms between poor health and loneliness. We hypothesized that loneliness leads to poorer mental and physical health. Alternatively however, poorer health may also lead to increased loneliness (4). In particular, reversed causality between poor mental health and increased loneliness may arise due to decreasing social support and resources of mentally ill individuals (4). In contrast, further research might find poorer physical health (i.e., accidents or severe illnesses) associated with less loneliness if treatments and social support are intensified. These potentially alternative pathways cannot be disentangled in a cross-sectional study, warranting further longitudinal research.

Nevertheless, our results do show a robust association between loneliness and higher mental healthcare expenditure. Even in the fully adjusted model, loneliness is associated with $10 \%$ (i.e., 340 million euros) additional mental healthcare expenditure annually (hypothesis 2a). This implies that (new) policies or societal programs targeted at combatting loneliness may have the potential to significantly reduce healthcare expenditure, particularly in mental healthcare. As shown in models one to six, loneliness may affect healthcare expenditure through different pathways (i.e., via worsened self-perceived health and psychological distress). Both economic and health aspects of loneliness should be considered in the development of new public health policies and societal programs in practice. Policies and programs combatting loneliness may even become more relevant in times of pandemic outbreaks and social restrictions as seen in the recent COVID-19 outbreak.

Secondly, our study is the first to reveal distinct associations of loneliness and healthcare expenditure across various age groups. While most policies and research associates loneliness with older age (2) and we expected healthcare expenditure to be higher for older age groups, our findings clearly indicate that severe loneliness is associated with relatively higher expenditure in younger adults (i.e., in aged 19-40) compared to older age groups, particularly for mental healthcare. This is consistent with researchers reporting that younger generations perceive higher levels of stress in today's more individualistic, high-performance society (32). Programs to address loneliness should target beyond older aged populations, and potential savings in (mental) healthcare expenditure should be considered in economic evaluations of programs. 
Marginal effects of loneliness on healthcare expenditures based on model 6 (fully adjusted) and 2 (basic), in age categories.

A Based on model 6: fully adjusted model

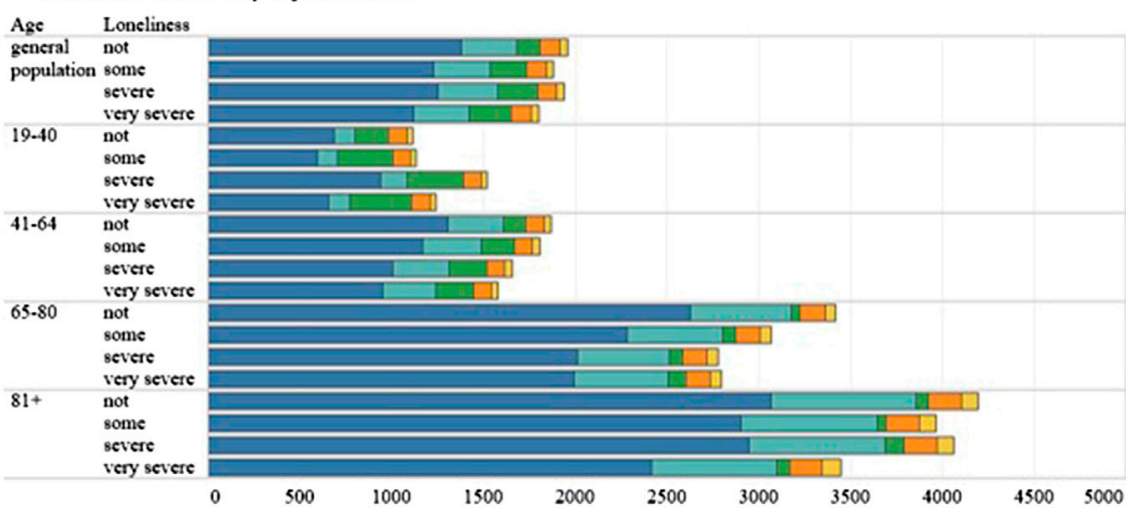

B Based on model 2: basic model

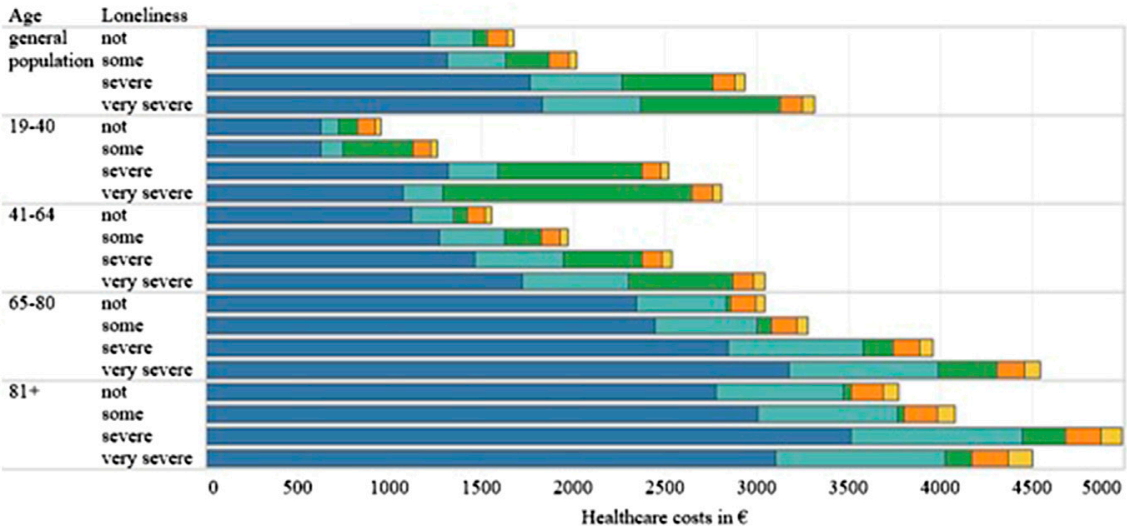

Measure Names

$\checkmark$ GP consultation expenditures

$\square$ GP other expenditures

Mental healthcare expenditures

Pharmaceutical care expenditures

- Specialized care expenditures

GP: general practitioner. A. model 6 is the fully adjusted model, which includes loneliness, demographic, SES,

lifestyle, self-perceived health, and psychological distress. B. model 2 is the basic model, which includes loneliness and demographic factors.

FIGURE 2 | Marginal effects of loneliness on healthcare expenditures based on model 6 (fully adjusted) and 2 (basic), in age categories. (A) Based on model 6: fully adjusted model. (B) Based on model 2: basic model. GP, general practitioner. A) model 6 is fully adjusted model, which includes loneliness, demographic, SES, lifestyle, self-perceived health, and psychological distress. B) model 2 is the basic model, which includes loneliness and demographic factors (The Netherlands, 2020).

\section{LIMITATIONS}

This study is not without limitations. First, some subgroups of the general population are under-represented in the Health Survey dataset. Examples include people of lower SES, with poorer health (33), or institutionalized citizens. However, survey design has taken this into account by oversampling low SES groups and the data were weighted for underrepresentation to mitigate these effects. Nevertheless, the associations for mental healthcare may still be underestimated as institutionalized citizens were not included. Second, this study produced cost estimates for the hypothesized relationships in the conceptual model. In view of the alternative mechanisms mentioned above, these estimates should only be interpreted very cautiously as an estimate of the healthcare related cost of loneliness. Simultaneously, we hope, the estimates indicate that loneliness not only comes with socioemotional costs, but also with financial costs. Third, more research is needed to further validate the cutoff points suggested by van Tilburg and de Jong-Gierveld (23).

\section{CONCLUSION}

Loneliness is associated with higher healthcare expenditure in all types of curative healthcare services independent of demographic-, socioeconomic- and lifestyle factors. For mental healthcare and GP spending, loneliness was associated with higher expenditure independent of demographic-, socioeconomic-, lifestyle factors, selfperceived health, and psychological distress. In the other categories, 
the association of loneliness and increased expenditure may be indirect (i.e., mediated in particular by self-perceived health and psychological distress). Furthermore, contrary to common perceptions of loneliness as an old-age problem, our results show that it plays a larger role in explaining healthcare expenditure in younger adults than it does in older adults. Societal programs targeting at loneliness thus have the potential to generate significant savings in healthcare expenditure, especially in mental healthcare and for younger people.

\section{DATA AVAILABILITY STATEMENT}

The dataset was provided by Statistics Netherlands and the Dutch Public Health Services. Requests to access these datasets should be directed to Statistics Netherlands, microdata@cbs.nl. Results are based on calculations by researchers from Maastricht University using non-public microdata from Statistics Netherlands.

\section{ETHICS STATEMENT}

The studies involving human participants were reviewed and approved by Ethical Review Committee of the Faculty of Health, Medicine and Life sciences of Maastricht University (FHML-

\section{REFERENCES}

1. Eurofound. European quality of life survey 2016: quality of life, quality of public services, and quality of society. Luxembourg: Publications Office of the European Union (2017).

2. Victor $\mathrm{CR}$, and Yang $\mathrm{K}$. The prevalence of loneliness among adults: a case study of the United Kingdom. J Psychol (2012) 146(1-2):85-104. doi:10.1080/ 00223980.2011 .613875

3. Beutel ME, Klein EM, Brähler E, Reiner I, Jünger C, Michal M, et al. Loneliness in the general population: prevalence, determinants and relations to mental health. BMC Psychiatr (2017) 17(1):97. doi:10.1186/s12888017-1262-x

4. Burholt V, and Scharf T. Poor health and loneliness in later life: the role of depressive symptoms, social resources, and rural environments. J Gerontol B Psychol Sci Soc Sci (2013) 69(2):311-24. doi:10.1093/geronb/gbt121

5. Lauder W, Mummery K, Jones M, and Caperchione C. A comparison of health behaviours in lonely and non-lonely populations. Psychol Health Med (2006) 11(2):233-45. doi:10.1080/13548500500266607

6. Macdonald SJ, Nixon J, and Deacon L. 'Loneliness in the city': examining socioeconomics, loneliness and poor health in the North East of England. Publ Health (2018) 165:88-94. doi:10.1016/j.puhe.2018.09.003

7. Hawkley LC, Burleson MH, Berntson GG, and Cacioppo JT. Loneliness in everyday life: cardiovascular activity, psychosocial context, and health behaviors. J Pers Soc Psychol (2003) 85(1):105. doi:10.1037/0022-3514. 85.1 .105

8. Cacioppo JT, Hawkley LC, Crawford LE, Ernst JM, Burleson MH, Kowalewski RB, et al. Loneliness and health: potential mechanisms. Psychosom Med (2002) 64(3):407-17. doi:10.1097/00006842-200205000-00005

9. Nummela $O$, Seppänen $M$, and Uutela $A$. The effect of loneliness and change in loneliness on self-rated health (SRH): a longitudinal study among aging people. Arch Gerontol Geriatr (2011) 53(2):163-7. doi:10.1016/j.archger. 2010.10.023

10. Hawkley LC, and Cacioppo JT. Loneliness matters: a theoretical and empirical review of consequences and mechanisms. Ann Behav Med (2010) 40(2): 218-27. doi:10.1007/s12160-010-9210-8

11. World Health Organization. Public spending on health: a closer look at global trends. Geneva, Switzerland: World Health Organization (2018).
REC/2019/025). The patients/participants provided their written informed consent to participate in this study.

\section{AUTHOR CONTRIBUTIONS}

RM, DW, PP, HB, DR, and MJ contributed to the design of the work. RM performed analyses. RM, DW, and PP drafted the first draft which was critically reviewed and approved for submission by all authors.

\section{CONFLICT OF INTEREST}

The authors declare that the research was conducted in the absence of any commercial or financial relationships that could be construed as a potential conflict of interest.

\section{SUPPLEMENTARY MATERIAL}

The Supplementary Material for this article can be found online at: https://www.frontiersin.org/articles/10.3389/ijph.2020.581286/ full\#supplementary-material.

12. Mihalopoulos C, Le LKD, Chatterton ML, Bucholc J, Holt-Lunstad J, Lim MH, et al. The economic costs of loneliness: a review of cost-of-illness and economic evaluation studies. Soc Psychiatr Psychiatr Epidemiol (2019) 55:823-6. doi:10. 1007/s00127-019-01733-7

13. Fulton L, and Jupp B. Investing to tackle loneliness: a discussion paper. London, UK: Social Finance (2015).

14. Landeiro F, Leal J, and Gray AM. The impact of social isolation on delayed hospital discharges of older hip fracture patients and associated costs. Osteoporos Int (2016) 27(2):737-45. doi:10.1007/s00198-015-3293-9

15. McDaid D, Park A, and Fernandez JL. Reconnections evaluations interim report. London, UK: Personal Services Research Unit (PSRU), London School of Economics and Political Science (2016).

16. Shaw JG, Farid M, Noel-Miller C, Joseph N, Houser A, Asch SM, et al. Social isolation and medicare spending: among older adults, objective social isolation increases expenditures while loneliness does not. J Aging Health (2017) 29(7): 1119-43. doi:10.1177/0898264317703559

17. Baumeister RF, and Leary MR. The need to belong: desire for interpersonal attachments as a fundamental human motivation. Psychol Bull (1995) 117(3) 497-529.

18. OECD. Health expenditure and financing. Paris, France: OECD (2019).

19. Kroneman M, Boerma W, van den Berg M, Groenewegen P, de Jong J, and van Ginneken E. The Netherlands: health system review, Health Syst Transit (2016) 18(2):1-240.

20. van den Brink CL, van Herten MH, and Boeker S. Gezondheidsmonitor 2012 The Dutch public health monitor 2012. Tijdschr Gezondheidswetenschappen (2017) 95(5):222-7. doi:10.1007/s12508-017-0067-0

21. de Boer WI, Buskens E, Koning RH, and Mierau JO. Neighborhood socioeconomic status and health care costs: a population-wide study in the Netherlands. Am J Publ Health (2019) 109:e1-7. doi:10.2105/AJPH.2019.305035

22. de Jong-Gierveld J, and Kamphuls F. The development of a Rasch-type loneliness scale. Appl Psychol Meas (1985) 9(3):289-99. doi:10.1177/014662168500900307

23. Van Tilburg $T$, and De Jong-Gierveld J. Cesuurbepaling van de eenzaamheidsschaal. Tijdschr Gerontol Geriatr (1999) 30:158-63.

24. World Health Organization. Body mass index: (2019). Available from: http://www.euro.who.int/en/health-topics/disease-prevention/nutrition/ a-healthy-lifestyle/body-mass-index-bmi.

25. Gezondheidsraad. Beweegrichtlijnen 2017. D Haag, editor. Den Haag, Netherlands: Gezondheidsraad (2017): 1-6. 
26. Manor O, Matthews S, and Power C. Dichotomous or categorical response? Analysing self-rated health and lifetime social class. Int J Epidemiol (2000) 29(1):149-57. doi:10.1093/ije/29.1.149

27. Kessler RC, Andrews G, Colpe LJ, Hiripi E, Mroczek DK, Normand SL, et al. Short screening scales to monitor population prevalences and trends in nonspecific psychological distress. Psychol Med (2002) 32(6):959-76. doi:10.1017/ s0033291702006074

28. Carini RM, Hayek JC, Kuh GD, Kennedy JM, and Ouimet JA. College student responses to web and paper surveys: does mode matter? Res High Educ (2003) 44(1):1-19. doi:10.1023/A:1021363527731

29. Austin PC, Ghali WA, and Tu JV. A comparison of several regression models for analysing cost of CABG surgery. Stat Med (2003) 22(17):2799-815. doi:10. $1002 /$ sim. 1442

30. Loeys T, Moerkerke B, De Smet O, and Buysse A. The analysis of zero-inflated count data: beyond zero-inflated Poisson regression. Br J Math Stat Psychol (2012) 65(1):163-80. doi:10.1111/j.2044-8317.2011.02031.x
31. StataCorp. Stata statistical software: release 15. College Station, TX: StataCorp LLC (2017).

32. AP Association. Stress in America: generation Z.: Stress in America ${ }^{\mathrm{TM}}$ Survey. Washington, UK: AP Association (2018).

33. Lorant V, Demarest S, Miermans PJ, and Van Oyen H. Survey error in measuring socio-economic risk factors of health status: a comparison of a survey and a census. Int J Epidemiol (2007) 36(6):1292-9. doi:10.1093/ $\mathrm{ije} /$ dym 191

Copyright $\odot 2021$ Meisters, Westra, Putrik, Bosma, Ruwaard and Jansen. This is an open-access article distributed under the terms of the Creative Commons Attribution License (CC BY 4.0). The use, distribution or reproduction in other forums is permitted, provided the original author(s) and the copyright owner(s) are credited and that the original publication in this journal is cited, in accordance with accepted academic practice. No use, distribution or reproduction is permitted which does not comply with these terms. 